\title{
Under the influence
}

\author{
Raglan Maddox (D) ,' Pamela M. Ling (D) , 2 Billie-Jo Hardy (D) , ${ }^{3}$ Mike Daube (D) ${ }^{4}$
}

${ }^{1}$ National Centre for

Epidemiology and Public Health, Australian National University,

Canberra, Australian Capital

Territory, Australia

${ }^{2}$ Center for Tobacco Control

Research and Education, School of Medicine, University of

California San Francisco, San

Francisco, California, USA

${ }^{3}$ Well Living House, St. Michael's Hospital, Unity Health Toronto,

Toronto, Ontario, Canada

${ }^{4}$ Health Sciences, Curtin

University, Perth, Western

Australia, Australia

\section{Correspondence to}

Dr Raglan Maddox, National Centre for Epidemiology and Public Health, Australian National University, Canberra, ACT 0200, Australia; raglan.maddox@anu.edu.au

\section{SLinked}

- http://dx.doi.org/10.1136/ tobaccocontrol-2020-056003

Check for updates

(C) Author(s) (or their employer(s)) 2021. No commercial re-use. See rights and permissions. Published by BMJ.

To cite: Maddox R, Ling PM, Hardy B-J, et al. Tob Control Epub ahead of print: [please include Day Month Year]. doi:10.1136/

tobaccocontrol-2020-056391
The tobacco industry has a long and welldocumented history of influencing, exploiting and misleading public health and research communities. $^{1-4}$ Starting with the 1953 'Tobacco Industry Research Committee, ${ }^{5}$, stakeholders affiliated with the tobacco industry have strategically promoted industry interests through the funding of research programmes and public health initiatives, in order to influence research agendas, manipulate the design, methods and conduct of research, affect interpretation of findings and selectively disseminate information through publications, conferences, forums and panels. ${ }^{1-4}$ These activities have enabled the tobacco industry to promote its versions of 'sound science' and 'good epidemiology' which have been designed to weaken consensus about the harms of tobacco use and second-hand smoke exposure. ${ }^{6}$ Academics and public health communities have sought to raise awareness about and challenge industry interference and manipulation, ${ }^{7-9}$ and some industry-funded research organisations such as the Council for Tobacco Research and the Center for Indoor Air Research were disbanded as part of the 1998 Master Settlement Agreement in the USA due to their extensively documented role in industry efforts to defraud the public. ${ }^{78}$ However, as Legg et al ${ }^{10}$ highlight, the approach has intensified and become more sophisticated over time.

A central tenet of the World Health Organization's Framework Convention on Tobacco Control (FCTC), ${ }^{11}$ Article 5.3, states: 'In setting and implementing their public health policies with respect to tobacco control, Parties shall act to protect these policies from commercial and other vested interests of the tobacco industry in accordance with national law'. ${ }^{11}$ There is now increasing evidence on the ways in which tobacco companies seek to position the industry as a strategic partner to public health, presenting themselves as scientific authorities who are promoting new products as solutions to concerns about commercial tobacco and as legitimate commentators on science and health research and policy. ${ }^{49912}$ For example, Philip Morris International (PMI) recently sponsored a series of articles published on The Australian newspaper website promoting the company's views on both the scientific evidence and public policy on vaping, ${ }^{13}$ an action that may arguably breach national tobacco advertising and promotion laws, ${ }^{13} 14$ while highlighting the use of any available opportunity to present the industry as 'part of the solution'. Such activities frequently fail to acknowledge clear conflicts of interest (COIs) ${ }^{4}$ and may be interpreted as attempts to actively undermine FCTC Article 5.3 implementation. ${ }^{11} 15$

The most lavishly funded new face of the tobacco industry was the 2017 establishment of the
Foundation for a Smoke-Free World with an original 'pledge agreement' of almost $\$ 1$ billion over 12 years from PMI, although a more recent version of the 'pledge agreement' seems to indicate reduced funding commitments. ${ }^{16} 17$ The PMI-funded Foundation and multinational tobacco companies promote the use of alternative tobacco products as 'tobacco harm reduction', a phrase co-opted from the illicit drugs arena, seeking to use the term exclusively to promote use of novel tobacco products and to renormalise the use of nicotine, helping to ensure the industry's long-term profitability as smoking rates drop. ${ }^{18} 19$ Tobacco companies adopted the term 'harm reduction' to enhance public relations, ${ }^{20}$ ignoring many tobacco control approaches, such as eliminating flavoured or menthol cigarettes, ${ }^{21}$ that reduce tobacco harm without promoting uptake of new tobacco products-actions that, like so many other evidence-based measures to reduce smoking, tobacco companies have fiercely opposed. ${ }^{22}$

Some researchers have sought to discount the importance of full financial COI disclosure, ${ }^{4} 2324$ attempting to generate a false equivalence between receiving industry funding and receiving public health funding, ${ }^{24}$ while tobacco company executives and those who support their position have equated tobacco industry funding with mandated government settlements, taxes and fees and philanthropic support. ${ }^{1025}$ Of especial note, there has been a recent surge in publications funded by the tobacco industry and associated groups.

We comment further on journals ignoring or weakening their policies prohibiting industryfunded articles and ignoring failures by tobacco industry stakeholders and their affiliates to disclose COI practices that can undermine the integrity and trustworthiness of public health research and initiatives. $^{1023}$

The PMI-funded Foundation for a Smoke-Free World's President, Derek Yach, recently published a letter in Nicotine and Tobacco Research entitled Tobacco Use Patterns in Five Countries During the COVID-19 Lockdown. ${ }^{26}$ While Yach reported that 'this survey was funded by the Foundation for a Smoke-Free World', the letter was silent about the Foundation's PMI funding, and the statement on 'Declaration of Interests' reads 'none declared'. Yet, this journal's Declaration of Interest policy clearly specifies that 'Science needs to be beyond reproach, particularly when financial vested interests operate, such as in nicotine and tobacco research' and 'The presence of undeclared sources of support and financial interests has the potential to undermine the credibility of published work regardless of whether or not the financial factors are linked to tobacco or non-tobacco industries'. ${ }^{27}$ Yach's failure to disclose that the Foundation is funded by 
a tobacco company is in our view inconsistent with the journal's policy, which is to 'disclose any financial or other substantive COI that might be suspected of influencing the outcomes reported'. ${ }^{27}$ Further, evidence suggests that the Foundation may function operationally to advance and amplify tobacco industry messaging and may continue to potentially influence research and public health. ${ }^{428}$ Although COI disclosure is not a failsafe, ${ }^{29}$ it is a minimum standard for scientific integrity.

As discussed by Legg et al, ${ }^{10}$ a special issue of Drugs and Alcohol Today is reported by the Foundation as aiming 'to explore progress towards the goals outlined' in the FCTC. ${ }^{12}$ As Legg et al ${ }^{10}$ outlined in this journal and also detailed on the Tobacco Tactics website, ${ }^{25}$ the PMI-funded Foundation reported that a number of articles by 'Foundation's staff, grantees and other prominent experts' describe strategies for 'improving' the FCTC and its implementation, ${ }^{12}$ without acknowledging that government partnership with the Foundation would be prohibited by Article 5.3 of the FCTC. The articles list the affiliations of authors who are Foundation employees and grantees, but some fail to disclose PMI financial support or interest in the research. ${ }^{123031}$ Articles written by O'Leary and Polosa ${ }^{30}$ and Glover et al ${ }^{31}$ list affiliations with their research centres of 'Excellence' and that they have received funding from the Foundation. However, they did not disclose PMI's funding of the Foundation or that Polosa ${ }^{25}$ has also received further tobacco industry funding. ${ }^{25} 32$ There is an absence of such detail in the respective COI statements among most of the articles listed. ${ }^{12} 3031$ The lack of disclosure seems to us to be inconsistent with the Drugs and Alcohol Today statement of its research and publishing ethics. While noting that the research published should have been conducted with the highest standards of rigour and integrity, this statement emphasises that there is a duty to report possible COIs. These possible COIs are specified as including undisclosed financial support for the research by an interested third party and further emphasises the need to provide 'the background to any financial support for the research from third parties and highlight any other possible COI ${ }^{33}$ The result of the approach taken in these articles is a quiet whitewashing of PMI's influence using Foundation grant making. Further, the irony is not lost that the leader of the PMIfunded Foundation was previously involved in development of the FCTC; as a result, PMI is now uniquely positioned to influence the FCTC through its established relationships, knowledge and experience.

Finally, the journal Tobacco Regulatory Science recently changed its policy to allow consideration of publications that are funded by the tobacco industry. ${ }^{34}$ The new Tobacco Regulatory Science policy states: 'Effective immediately, articles that have received funding from a tobacco company can be submitted for review and consideration for publication in Tobacco Regulatory Science'. ${ }^{34}$ The change in policy is described as being linked to a Society for Research on Nicotine and Tobacco (SRNT) policy, ${ }^{34}$ which may confer even more legitimacy to publishing tobacco industry research. However, in our view, this is inconsistent with the SRNT position on membership which details that individuals employed by a 'company that is part of the tobacco industry or a company that is partially or wholly owned by a company that is part of the tobacco industry are not eligible for membership'. ${ }^{35}$ COI disclosure is necessary, but not sufficient to identify and manage scientific COI. ${ }^{29}{ }^{36}$ More concerning is that in some instances, merely relying on disclosure may worsen bias ${ }^{37}$ further emboldening organisations like PMI and highlighting the need for stronger mechanisms to address COI. For example, reliance on disclosure alone can leave the actual COI unaddressed. While disclosure shifts the COI to 'open bias', as opposed to undisclosed or 'secret bias', it may also be perceived as absolving a person from their responsibility of managing their COI. Further, voluminous or self-styled disclosure sometimes generates 'white noise' which can obscure conflicts. ${ }^{23} 38$

Together, and complementing the discussion by Legg et al, ${ }^{10}$ these examples highlight the role of scientific journals in enabling tobacco industry stakeholders to influence production of research and public health policy to further industry interests, as well as structural failures to hold them to account in a transparent manner. Some affiliated with the industry claim that journal policies against acceptance of industry-funded research constitute 'censorship', an argument reminiscent of similar claims made in countries where tobacco advertising bans have been mooted and implemented. Rather, these policies recognise the fundamental, irreconcilable conflict between the tobacco industry's interests and public health, as set out in the FCTC and its guidelines. ${ }^{1139}$ The tobacco industry continues to reinvent itself and to reshape research and public health debates, prioritising profits over people. This is of concern not only for ethical reasons, ${ }^{5} 91140$ but also because these efforts appear to be a wellcoordinated initiative to promote the tobacco industry's interests by presenting tobacco companies as part of the solution to the tobacco problem. ${ }^{19}$

While efforts to exploit relationships with scientific journals are not new, ${ }^{41}$ the continuing steady drip of industry-funded articles in scientific journals should raise concern. Journals such as Tobacco Control, BMJ and PLoS Medicine have taken a principled stance against the acceptance of tobacco industryfunded research. ${ }^{42-45}$ As scientists and members of the public health community, it is our responsibility to expose when and in what manner tobacco industry interests intersect with and influence research and public health. ${ }^{40}$ We strongly support policies prohibiting tobacco industry-funded articles and agree that practices such as fully declaring interests in peer-reviewed journals must be clearly set out, consistently monitored and enforced. Where these policies are lacking, they should be introduced.

Analogous to FCTC Article 5.3 and the 2020 World No Tobacco Day theme, 'Protecting youth from industry manipulation and preventing them from tobacco and nicotine use', we must insulate both scientific publishing and policy-making from tobacco industry influence. ${ }^{11}$ As work to strengthen the implementation of the FCTC continues, both governments and scientists need support and encouragement to end, not embrace, tobacco industry influence. ${ }^{1546}$ The 'merchants of doubt' ${ }^{1}$ and the actors who work with them should not be permitted to claim legitimacy or credibility in the scientific arena. ${ }^{3}$

Twitter Raglan Maddox @RaglanMaddox and Billie-Jo Hardy @BillieJ_Hardy

Contributors All authors have contributed substantially to conception, drafting and finalisation of this manuscript.

Funding The authors have not declared a specific grant for this research from any funding agency in the public, commercial or not-for-profit sectors.

Competing interests None declared.

Patient consent for publication Not required.

Provenance and peer review Commissioned; internally peer reviewed.

\section{ORCID iDs}

Raglan Maddox http://orcid.org/0000-0002-2770-0686

Pamela M. Ling http://orcid.org/0000-0001-6166-9347

Billie-Jo Hardy http://orcid.org/0000-0003-3380-8076

Mike Daube http://orcid.org/0000-0002-3479-2785

\section{REFERENCES}

1 Oreskes N, Conway EM. Merchants of doubt: how a handful of scientists obscured the truth on issues from tobacco smoke to global warming. Bloomsbury Publishing USA, 2011. 
2 Bero LA. Tobacco industry manipulation of research. Public Health Rep 2005;120:200-8.

3 White J, Bero LA. Corporate manipulation of research: strategies are similar across five industries. Stanford Law and Policy Review 2010;21:105.

4 van der Eijk Y, Bero LA, Malone RE. Philip Morris International-funded 'Foundation for a Smoke-Free World': analysing its claims of independence. Tob Control 2019;28:712-8

5 Brandt AM. Inventing conflicts of interest: a history of tobacco industry tactics. Am J Public Health 2012;102:63-71.

6 Ong EK, Glantz SA. Constructing "sound science" and "good epidemiology": tobacco, lawyers, and public relations firms. Am J Public Health 2001;91:1749-57.

7 Schick SF, Glantz SA. Old ways, new means: tobacco industry funding of academic and private sector scientists since the master settlement agreement. Tob Control 2007;16:157-64.

8 Master Settlement Agreement. Master settlement agreement between 46 state attorneys general and participating tobacco manufacturers, 1998. Available: https:// 1 li23g1as25g1r8so11ozniw-wpengine.netdna-ssl.com/wp-content/uploads/2020/09/ MSA.pdf

9 Waa A, Robson B, Gifford $H$, et al. Foundation for a smoke-free world and healthy Indigenous futures: an oxymoron? Tob Control 2020;29:237-40.

10 Legg T, Legendre M, Gilmore A. Paying lip service to publication ethics: scientific publishing practices and the foundation for a smoke-free world. Tobacco Control 2021.

11 World Health Organization. Framework convention on tobacco control: WHO regional office for South-East Asia; 2004

12 Foundation for a Smoke-Free World. Foundation for a smoke-free world drugs and alcohol Journal special issue, 2020. Available: https://www.smokefreeworld.org/ drugs-and-alcohol-journal-special-issue/

13 The Australian. Follow science to the moon, 2020. Available: https://www. theaustralian.com.au/sponsored/rp9Rxv493P9nQTUOkEni/follow-science-to-themoon/?utm_source=taboola\&utm_medium=referral

14 Meade A. Philip Morris-sponsored articles in the Australian could breach tobacco advertising laws The Guardian; 2020.

15 Malone RE, Bialous SA. WHO FCTC article 5.3: promise but little progress. Tob Control 2014:23:279-80.

16 Foundation for a Smoke-Free World. Foundation for a smoke-free world FAQs, 2021. Available: https://www.smokefreeworld.org/our-vision/frequently-asked-questions/

17 Foundation for a Smoke-Free World, PMI Global Services Inc. Amended and Restated Pledge agreement. New York: Foundation for a Smoke-Free World and PMI Global Services Inc, 2020. https://www.smokefreeworld.org/governance/

18 Ling PM, Glantz SA. Tobacco company strategies to identify and promote the benefits of nicotine. Tob Control 2019:28:289-96.

19 Moore M, McKee M, Daube M. Harm reduction and e-cigarettes: distorting the approach. J Public Health Policy 2016;37:403-10.

20 Peeters S, Gilmore AB. Understanding the emergence of the tobacco industry's use of the term tobacco harm reduction in order to inform public health policy. Tob Control 2015;24:182-9.

21 Rossheim ME, Livingston MD, Krall JR, et al. Cigarette use before and after the 2009 flavored cigarette ban. J Adolesc Health 2020;67:432-7.

22 Yang YT, Glantz S. San Francisco voters end the sale of flavored tobacco products despite strong industry opposition. Ann Intern Med 2018;169:708-9.

23 Phillips CV. Warning: anti-tobacco activism may be hazardous to epidemiologic science. Epidemiol Perspect Innov 2007;4:13-16.

24 Phillips CV. Commentary: lack of scientific influences on epidemiology. Int J Epidemiol 2008:37:59-64.
25 Tobacco Control Research Group at the University of Bath. Tobacco Tactics Foundation for a Smoke-Free World Centres of Excellence, 2020. Available: https:// tobaccotactics.org/wiki/foundation-for-a-smoke-free-world-centres-of-excellence/ [Accessed 16 Nov 2020].

26 Yach D. Tobacco use patterns in five countries during the COVID-19 Lockdown. Nicotine Tob Res 2020;22:1671-2.

27 Nicotine \& Tobacco Research. Nicotine \& Tobacco Research: Policy on Conflicts of Interest (COI), 2020. Available: https://academic.oup.com/DocumentLibrary/NTR/ NTR\%20Conflict\%20of\%20Interest\%20Policy.pdf

28 Odierna DH, Forsyth SR, White J, et al. The cycle of bias in health research: a framework and toolbox for critical appraisal training. Account Res 2013;20:127-41.

29 Bero LA, Grundy Q. Not all influences on science are conflicts of interest. Am J Public Health 2018;108:632-3.

30 O'Leary R, Polosa R. Tobacco harm reduction in the 21st century. Drugs and Alcohol Today 2020;20:219-34

31 Glover M, Patwardhan P, Selket K. Tobacco smoking in three "left behind" subgroups: indigenous, the rainbow community and people with mental health conditions. Drugs and Alcohol Today 2020;20:263-81.

32 Tobacco Tactics. Foundation for a smoke-free world. 2021. Available: https:// tobaccotactics.org/wiki/foundation-for-a-smoke-free-world/[Accessed 22/04/2021].

33 Emerald Publishing. Research \& publishing ethics, 2020. Available: https://www.emer aldgrouppublishing.com/our-services/authors/research-publishing-ethics

34 Tobacco Regulatory Science. New tobacco company publication policy, 2020. Available: https://tobreg.org/manuscript-submission/tobacco-industry-policystatement/

35 Society for Research on Nicotine and Tobacco. Society for research on nicotine and tobacco membership, 2021. Available: https://www.srnt.org/page/Membership

36 Bero LA, Grundy Q. Why having a (nonfinancial) interest is not a conflict of interest. PLoS Biol 2016;14:e2001221.

37 PLoS Medicine Editors. Does conflict of interest disclosure worsen bias? PLoS Med 2012;9:e1001210.

38 Cosgrove L, Krimsky S. A comparison of DSM-IV and DSM-5 panel members financial associations with industry: a pernicious problem persists. PLOS Med 2012:9:e1001190.

39 World Health Organization. Guidelines for implementation of the who FCTC. Geneva: World Health Organization, 2013

40 Gasparini M, Tarquini D, Pucci E, et al. Conflicts of interest and scientific societies. Neurol Sci 2020:41:2095-102

41 Elias J, Ling PM. Invisible smoke: third-party endorsement and the resurrection of heat-not-burn tobacco products. Tob Control 2018;27:s96-101.

42 IJERPH Editorial Office. The New International Journal of Environmental Research and Public Health (IJERPH) Policy Concerning Tobacco Company Funding. Int J Environ Res Public Health 2018;15:2831-2.

43 PLoS Medicine Editors. A new policy on tobacco papers. PLoS Med 2010;7:e1000237.

44 Malone RE. Changing tobacco control's policy on tobacco industry-funded research. Tob Control 2013;22:1-2.

45 Godlee F, Malone $\mathrm{R}$, Timmis A, et al. Journal policy on research funded by the tobacco industry. Thorax 2013;68:1090-1.

46 Malone RE. 'Stop me before I kill again': why Philip Morris international needs governments' help to quit smoking, and why governments need more pressure to do so. Tob Control 2018;27:121-2.

47 Stopping Tobacco Organizations and Products. Addiction at any cost: Philip Morris international uncovered, 2020. Available: https://exposetobacco.org/wp-content/ uploads/STOP Report_Addiction-At-Any-Cost.pdf 